\title{
Prototipe Penggerak Atap Kanopi Otomatis Menggunakan Sensor Cahaya, Sensor Hujan Dan Sensor Suhu Berbasis Mikrokontroler ATMega16
}

\author{
I Made Adi Wijaya ${ }^{1}$, I Gusti Agung Putu Raka Agung ${ }^{2}$, Pratolo Rahardjo ${ }^{3}$ \\ Program Studi Teknik Elektro, Fakultas Teknik, Universitas Udayana Denpasar - Bali \\ Email : adyipunx@yahoo.com ${ }^{1}$, igapraka@yahoo.co.id ${ }^{2}$, pratolo@unud.ac.id ${ }^{3}$
}

\begin{abstract}
Abstrak
Desain rumah minimalis terkadang mengabaikan faktor kenyamanan seperti sirkulasi udara dan pencahayaan langsung yang mengakibatkan peningkatan kelembaban udara di dalam rumah dan suhu udaranya menjadi panas. Pemberian sistem kontrol pada bagian rumah dapat membantu sirkulasi udara menjadi lebih baik. Pada paper ini, prototipe penggerak atap kanopi otomatis menggunakan sensor cahaya, sensor hujan, dan sensor suhu berbasis mikrokontroler ATMega16 diajukan sebagai solusi permasalahan ini. Prototype ini menggunakan bahasa pemrograman pada software BASCOM AVR dan software PROTEUS untuk simulasi rangkaian. Sensor cahaya berupa LDR akan mendeteksi perubahan intensitas cahaya, yaitu pada saat gelap menghasilkan tegangan $1,17 \mathrm{~V}$ dan berlogika 0 dan pada saat terang menghasilkan tegangan 4,30V dan berlogika 1 . Sensor hujan digunakan untuk mendeteksi adanya air pada saat terjadi hujan, yaitu pada kondisi hujan menghasilkan tegangan $1,83 \mathrm{~V}$ dan berlogika 0 , sedangkan pada kondisi tidak hujan menghasilkan tegangan 4,70V dan berlogika 1 . Sensor suhu LM35 digunakan untuk mendeteksi perubahan suhu yang terjadi, yaitu pada saat suhu kurang dari $29^{\circ} \mathrm{C}$ akan berlogika 0 dan pada saat suhu lebih dari $29^{\circ} \mathrm{C}$ akan berlogika 1 . Seluruh kondisi yang dihasilkan oleh ketiga sensor tersebut akan dikonversikan melalui ADC sehingga dapat memberikan input logika pada mikrokontroler untuk menggerakkan motor servo menutup atau membuka atap kanopi.
\end{abstract}

Kata Kunci : Mikrokontroler ATMega16, sensor cahaya, sensor hujan, sensor suhu, motor servo.

\begin{abstract}
Small house design, sometimes ignoring comfort factors such as air circulation and direct sunlight that can make humidity increase and higher temperature inside the house. Giving a controll system at the part of the house can make the air circulation better. In this paper, the prototype design of automatic roof canopy drive using a light sensor, rain sensor, and an ATMega16 microcontroller based temperature sensor is used to solve the problem. This prototype uses the programming language in BASCOM AVR software and PROTEUS software for circuit simulation. Light sensor in the form of LDR will detect changes in light intensity, that is when dark produces a voltage of $1.17 \mathrm{~V}$ and logic 0 and when light produces a voltage of $4.30 \mathrm{~V}$ and logic 1 . Rain sensor is used to detect the presence of water in the event of rain, that is in conditions the rain produces a $1.83 \mathrm{~V}$ voltage and logic 0 , whereas in the absence of rain it produces a voltage of $4.70 \mathrm{~V}$ and logic 1 . The LM35 temperature sensor is used to detect temperature changes that occur, namely when temperatures less than $29^{\circ} \mathrm{C}$ will logic 0 and when the temperature is over from $29^{\circ} \mathrm{C}$ will logic 1 . All conditions generated by the three sensors will be converted through the $A D C$ so that it can provide logic input to the microcontroller to drive the servo motor to close or open the canopy roof.
\end{abstract}

Keywords: ATMega16 microcontroller, light sensor, rain sensor, temperature sensor, servo motor.

\section{PENDAHULUAN}

Pembangunan rumah baru saat ini sangat meningkat, terutama pada daerah perkotaan di mana lahan yang digunakan untuk membangun rumah semakin sedikit, sedangkan permintaan kepemilikan rumah baru semakin meningkat. Banyak pengembang perumahan yang membuat perumahan dengan desain minimalis, selain harga yang terjangkau oleh kalangan masyarakat tingkat ekonomi menengah, desain perumahan minimalis juga sedang menjadi trend saat ini. Terkadang penghuni perumahan minimlis salah satunya perumahan tipe 36 yang memiliki luas bangunan hanya $36 \mathrm{~m}^{2}$, merenovasi kembali desain 
rumah yang telah di bangun oleh pengembang perumahan minimalis sehingga dapat digunakan untuk memenuhi kebutuhan yang diinginkan seperti memperluas atau menambah ruang lainya. Namun, desain baru yang telah dibangun oleh penghuni rumah minimalis tersebut terkadang mengabaikan faktor kenyamanan bagi penghuni itu sendiri, terutama pada rumah minimalis yang mendesain dapur pada bagian belakang rumah yang tidak memiliki ventilasi udara karena berbatasan langsung dengan dinding atau tembok terhadap rumah lain yang berada di belakangnya, dikarenakan penghuni rumah minimalis tersebut memperluas atau menambah ruang lainnya seperti kamar tidur, ruang tamu dan halaman depan rumah.

Pada saat memasak, asap atau udara yang dihasilkan hanya tersebar pada ruangan yang ada sehingga dapat mengganggu pernapasan penghuninya. Desain kamar mandi yang terletak di samping dapur serta minimnya sinar matahari yang masuk sampai ke dalam rumah dapat mengakibatkan kelembaban di dalam ruangan bakteri dapat berkembang biak.

Solusi dari permasalahan tersebut adalah dengan merancang Prototipe Penggerak Atap Kanopi Otomatis Menggunakan Sensor Cahaya, Sensor Hujan dan Sensor Suhu Berbasis Mikrokontroler ATMega16. Perangkat ini akan menggunakan tiga buah sensor yaitu sensor cahaya (LDR), sensor hujan, dan sensor suhu. Sensor cahaya digunakan untuk mengetahui intensitas cahaya pada saat keadaan terang atau gelap dengan menggunakan rangkaian komparator atau pembanding, sensor hujan digunakan untuk mengetahui adanya air pada saat terjadi hujan, sedangkan sensor suhu digunakan untuk mendeteksi perubahan suhu yang terjadi akibat aktifitas masak memasak sehingga asap yang dihasilkan tidak mencemari udara pada ruangan lain tetapi dapat mengarah keluar melalui atap kanopi yang terbuka. Data dari ketiga sensor akan diterima oleh mikrokontroler yang kemudian ditampilkan ke LCD dan selanjutnya data tersebut akan digunakan untuk memberikan perintah motor servo untuk bergerak sesuai dengan input kondisi yang akan mempengaruhi pergerakan atap kanopi untuk membuka atau menutup .

\section{KAJIAN PUSTAKA}

\subsection{Mikrokontroler}

Mikrokontroler adalah suatu alat elektronik berbasis digital yang mempunyai input dan output serta mampu mengendalikan program yang bisa ditulis dan dihapus dengan suatu cara khusus, cara kerja mikrokontroler adalah membaca dan menulis data [1].

\subsection{Mikrokontroler AVR}

Perusahaan Atmel merupakan perusahaan pertama yang memperkenalkan Mikrokontroler AVR ke pasaran sekitar tahun 1997, dengan produk mikrokontroler seri AT89S51/52 yang sampai sekarang masih banyak digunakan. Standar mikrokontroler AVR memiliki arsitektur 8 bit, semua instruksi disusun dalam kode 16 bit dan sebagian besar instruksi diproses dalam satu siklus clock, sedangkan MCS51 membutuhkan 12 siklus clock [2].

\subsection{Mikrokontroler ATMega16}

Mikrokontroler ATMega16 memiliki beberapa fitur antara lain [3]:

a. Mikroprosesor yang memiliki sistem 8 bit berbasis RISC dengan kecepatan maksimal $16 \mathrm{MHz}$.

b. Kelebihan memory flash $16 \mathrm{~Kb}$, SRAM sebesar 512 byte, dan Electrically Erasable Programmable Read Only Memory (EEPROM) sebesar 512 byte.

c. ADC internal dengan tingkat keakuratan 10 bit sebanyak 8 channel.

d. USART dengan kecepatan maksimal 2,5Mbps.

Gambar 1. Merupakan susunan pin ATMEGA16.

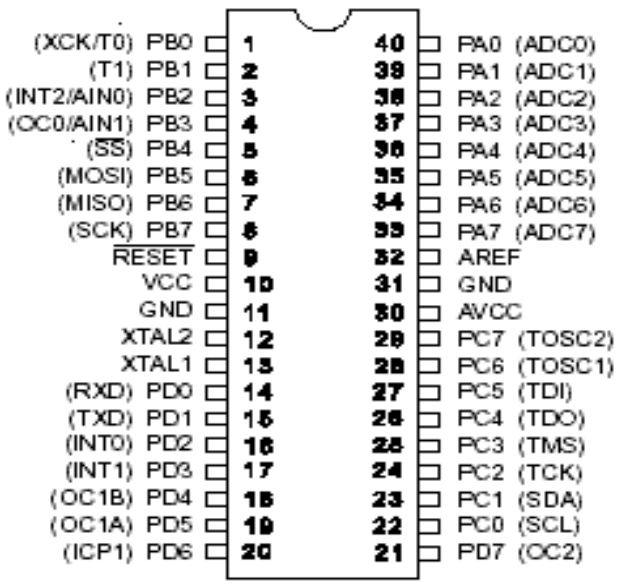

\subsection{Atap Kanopi}

Gambar 1. Susunan Pin ATMega1

Atap berfungsi sebagai pelindung dan penutup seluruh ruangan yang ada di bawahnya terhadap panas, hujan, angin, debu. Atap pada rumah berfungsi sebagai penahan air hujan masuk secara langsung ke dalam rumah. Atap rumah juga berfungsi untuk melindungi rumah dari teriknya sinar matahari langsung pada siang hari [4]. Nama lain dari Kanopi adalah Canopy yang digunakan 
sebagai penutup pada pintu, balkon dan juga sebagai atap pelindung mobil atau kendaraan lainya dari sinar matahari langsung dan air hujan.

\subsection{Sensor Hujan}

Sensor hujan atau sensor air berfungsi untuk mendeteksi adanya air pada saat terjadinya hujan. Sensor ini menggunakan panel sebagai detektor air. Gambar 2 merupakan rangkaian sensor hujan.

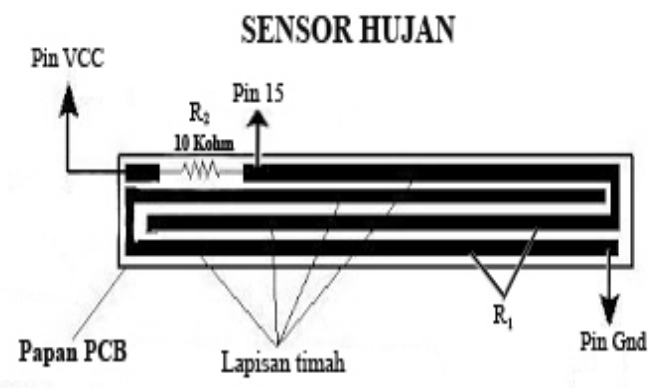

Gambar 2. Rangkaian Sensor Hujan.

Cara kerja sensor hujan yaitu pada saat air hujan mengenai tembaga panel sensor, maka akan terjadi proses penguraian elektrolit oleh arus listrik karena air hujan termasuk ke dalam cairan elektyang yang dapat menghantarkan arus listrik, walaupun sangat kecil dan proses ini akan menyebabkan keadaan aktif [5].

\subsection{Sensor Suhu LM35}

LM35 adalah komponen sensor suhu yang hampir menyerupai transistor TO-92. LM35 mampu mengukur suhu hingga $100^{\circ}$ Celcius. Gambar 3 merupakan rangkaian suhu LM35..

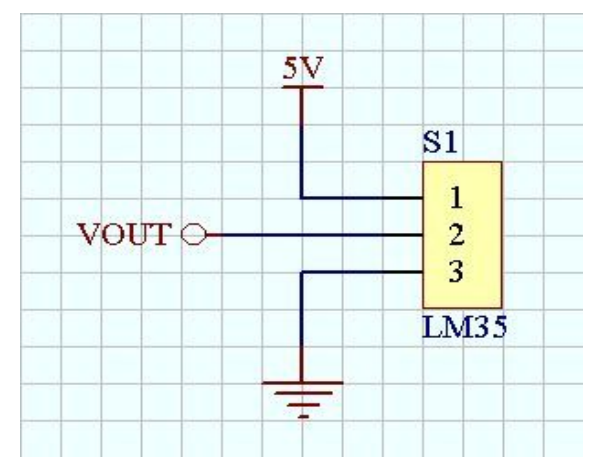

Gambar 3. Sensor Suhu LM35

Skala linear tegangan keluaran suhu terukur yakni 10 milivolt per 1 derajad Celcius, komponen ini sangat cocok digunakan pada aplikasi seperti termometer digital, kontrol suhu mesin pasteurisasi, kontrol suhu mesin penetas telur atau kontrol fan radiator mobil [5].

\section{METODELOGI PENELITIAN}

Menjelaskan tahapan yang diambil dalam melakukan penelitian

\subsection{Diagram Alir Perancangan}

Diagram alir prototipe penggerak atap kanopi otomatis menggunakan sensor cahaya dan sensor hujan berbasis mikrokontroler ATMega16 ditunjukkan pada Gambar 4.

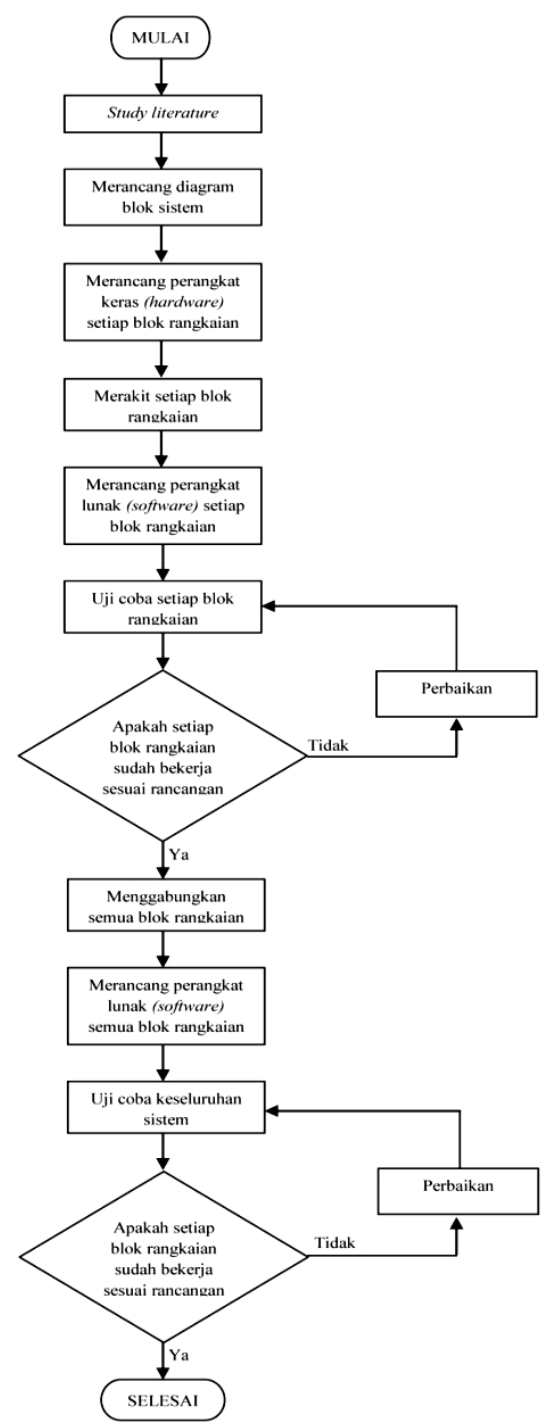

Gambar 4. Diagram Alir Perancangan Prototipe Penggerak Atap Kanopi Otomatis menggunakan sensor cahaya, sensor hujan dan sensor suhu berbasis Mikrokontroler ATMega16

\subsection{Perancangan Perangkat Keras}

Perancangan perangkat keras dilakukan pada implementasi prototipe penggerak atap 


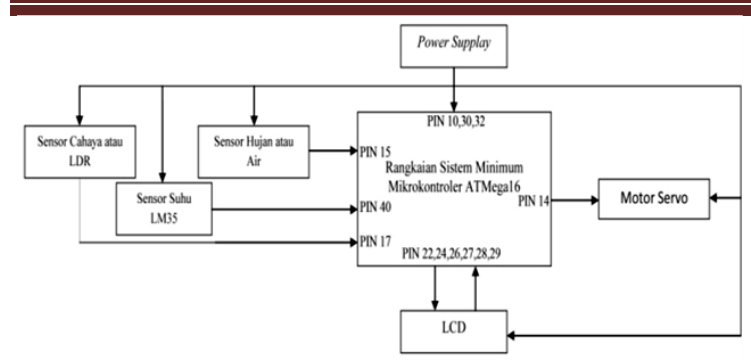

Gambar 5. Diagram Blok Prototipe Penggerak Atap Kanopi Otomatis Menggunakan Sensor Cahaya, Sensor Hujan dan Sensor Suhu LM35 Berbasis Mikrokontroler ATMega16

kanopi secara otomatis menggunakan sensor cahaya, sensor hujan dan sensor suhu berbasis mikrokontroler ATMega16 diantaranya, perancangan prototipe atap kanopi, simulasi rangkaian keseluruhan sistem yang menggunakan software proteus pro 7.7.Sp2, serta perancangan skematik dan lay out PCB menggunakan software PCB Wizard 3.50 Pro Unlimited. Diagram blok prototipe penggerak atap kanopi otomatis menggunakan sensor cahya dan hujan berbasis mikrokontroler ATMega16 ditunjukkan pada Gambar 5.

\section{HASIL DAN PEMBAHASAN}

\subsection{Realisasi Hasil Perancangan}

Realisasi Prototipe Penggerak Atap Kanopi Otomatis Menggunakan Sensor Cahaya, Sensor Hujan dan Sensor Suhu Berbasis Mikrokontroler ATMega16 dibagi menjadi dua yaitu prototipe perumahan minimlis dan rangkaian penggerak atap kanopi. Pada perancangan prototipe perumahan minimalis ini digunakan untuk meletakkan motor servo dan atap kanopi yang dapat digerakkan secara otomatis. Untuk letak motor servo dan atap kanopi ditunjukkan pada Gambar 6 yang merupakan tampak belakang prototipe perumahan minimalis.

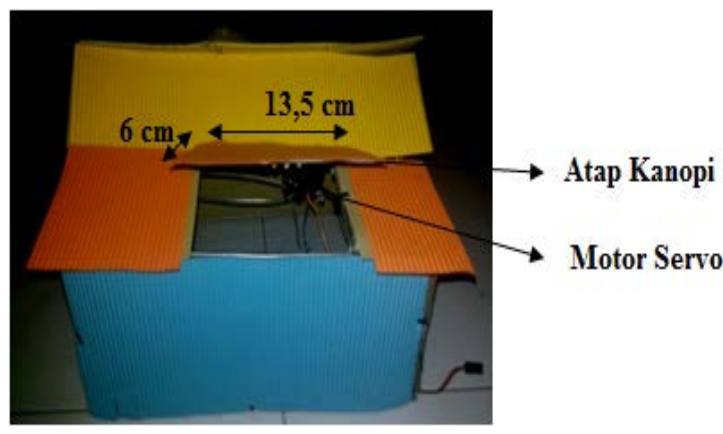

Gambar 6 Prototipe Perumahan Minimalis.

\subsubsection{Pengujian Rangkaian Sensor Cahaya}

Gambar 7 rangkaian penggerak atap kanopi yang tampak dari atas sedangkan Gambar 8 menunjukkan rangkaian penggerak atap kanopi yang terdiri dari rangkaian utama mikrokontroler ATMega16 dan rangkaian penstabil tegangan sensor suhu yaitu rangkaian LM2596.

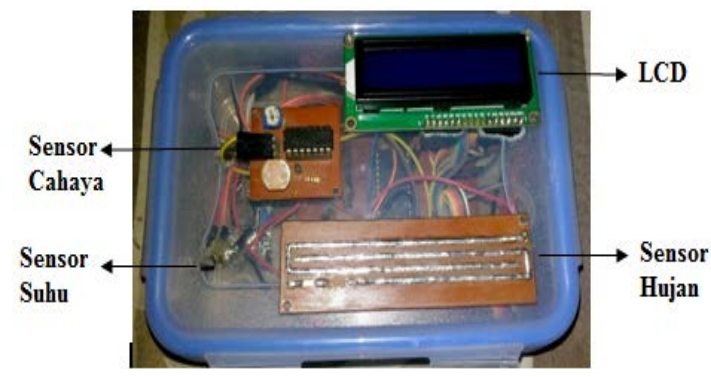

Gambar 7 Tampak Atas Rangkaian Penggerak Atap Kanopi.

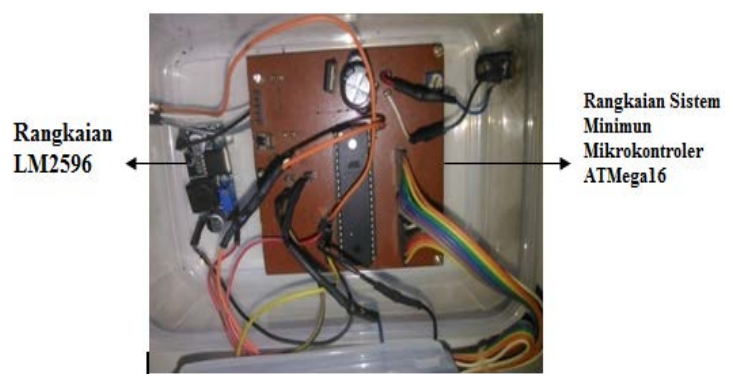

Gambar 8 Tampak Atas Bagian Dalam Rangkaian Penggerak Atap Kanopi.

\subsection{Pengujian dan Pembahasan}

\subsubsection{Pengujian Rangkaian Sistem Minimum Mikrokontroler ATMega dan Rangkaian LCD \\ Pengujian rangkaian sistem minimum} mikrokontroler ATMega16 bertujuan untuk mengetahui apakah rangkaian sistem minimum dapat bekerja dengan baik. AVR USB downloader digunakan untuk menguji sistem minimum mikrokontroler ATMega16 dan dapat dilihat pada Gambar 9. AVR USB downloader akan dihubungkan pada pin MOSI, MISO, SCK dan RESET mikrokontroler ATMega16 untuk mengirimkan program yang telah dibuat pada software BASCOM AVR.

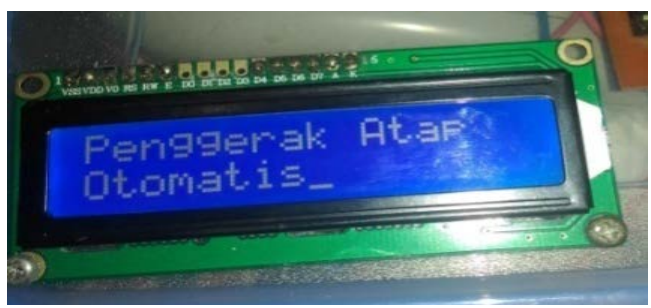

Gambar 9 Pengujian Rangkaian Sistem Minimum Mikrokontroler ATMega16 Dengan Menampilkan Tulisan Pada LCD 
Pengujian sensor cahaya dilakukan dengan mengukur tegangan output dari sensor cahaya atau LDR yang terhubung langsung dengan pin mikrokontroler ATMega16 yaitu pin 18, dan pengujian rangkaian pada tampilan LCD menggunakan program pada pengujian secara keseluruhan. Sensor cahaya bekerja berdasarkan perubahan intensitas cahaya, semakin besar intensitas cahaya maka semakin kecil tahanan atau resistansi yang dihasilkan, dan sebaliknya semakin kecil intensitas cahaya maka semakin besar tahanan atau resistansi yang dihasilkan.

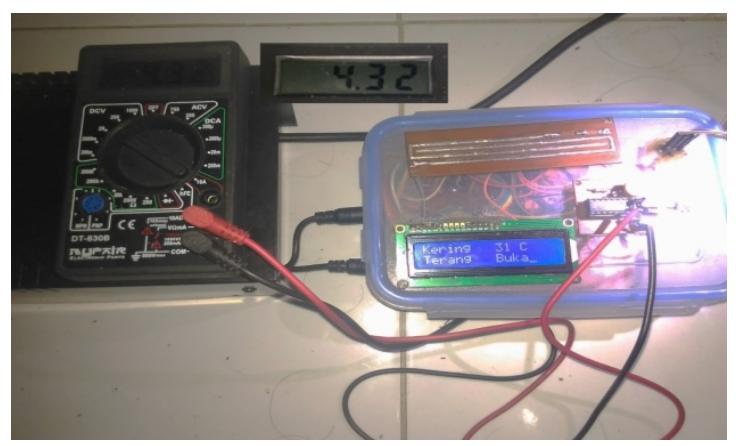

Gambar 10 Pengujian Dan Pengukuran Tegangan Sensor Cahaya Atau LDR Saat Cahaya Terang

\subsubsection{Pengujian Sensor Hujan}

Pada pengujian sensor hujan dilakukan dengan pengukuran pada tegangan output yang terhubung langsung pada pin mikrokontroler ATMega16 yaitu pin 15, dan pengujian rangkain sensor hujan pada hasil kondisi tampilan LCD menggunakan program pengujian secara keseluruhan. Pengujian sensor hujan dilakukan pada saat tidak adanya air atau pada saat kondisi tidak terjadi hujan dan pada saat adanya air atau pada saat terjadi hujan.

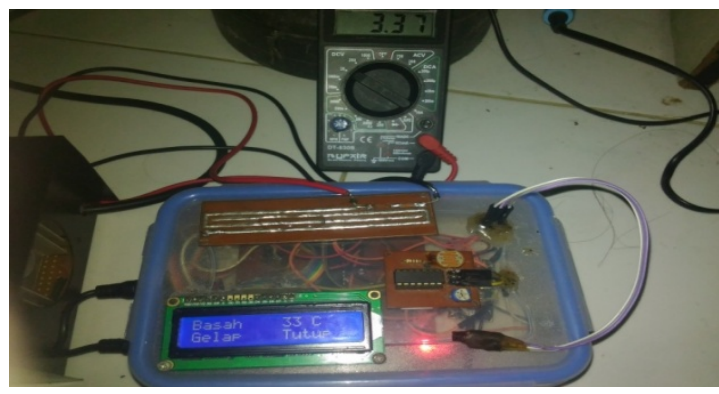

Gambar 11 Pengujian Dan Pengukuran Tegangan Sensor Hujan Pada Saat Terjadi Hujan.

\subsubsection{Pengujian Sensor Suhu LM35}

Pada pengujian sensor suhu LM35 dilakukan dengan mengukur tegangan output yang langsung terhubung dengan mikrokontroler ATMega16 pada pin 40 dan pengTabel 1. Kondisi dan Logika Program ujian menggunakan tampilan hasil pengukuran suhu pada LCD serta thermometer pengukur suhu. Pada realisasinya rangkaian sensor suhu LM35 memerlukan penstabil tegangan sehingga digunakan modul tambahan yaitu LM2596. Fungsi dari modul LM2596 yaitu untuk menaikkan tegangan DC dan memberikan tegangan stabil $5 \mathrm{~V}$ pada sensor suhu LM35.

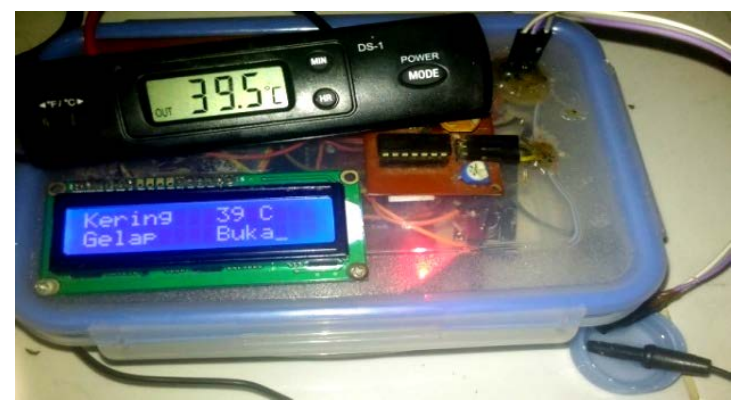

Gambar 12 Pengujian Sensor Suhu LM35 Pada Suhu $39^{\circ} \mathrm{C}$.

\subsubsection{Pengujian Motor Servo}

Pengujian motor servo dilakukan dengan menentukan besarnya nilai pulsa byte pada program bascom AVR yang digunakan untuk menentukan waktu pulse motor servo sehingga menghasilkan sudut yang diinginkan. Pada pengujian motor servo menggunakan program bascom AVR, software simulasi PROTEUS dimana pada software tersebut menggunakan osciloskop untuk mengetahui lebar pulsa motor servo, dan motor servo yang digunakan yaitu Tower Pro MG 90S Micro Servo. Gambar 13 merupakan percobaan pada sudut motor servo $90^{\circ}$,

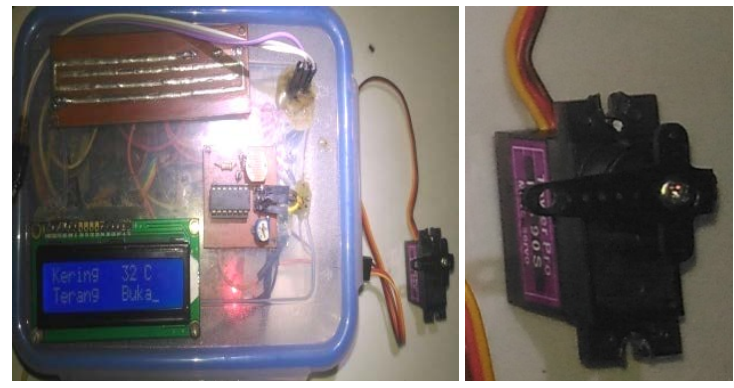

Gambar 13 Pengujian Motor Servo sudut $90^{\circ}$.

\subsubsection{Pengujian Secara Keseluruhan Berdasarkan Tabel Kondisi}

Pengujian secara keseluruhan dilakukan berdasarkan pada tabel kondisi yang telah dirancang pada perangkat lunak sistem. Logika untuk kondisi tersebut dapat dilihat pada Tabel 1. 


\begin{tabular}{|c|c|c|c|c|c|}
\hline \multirow{2}{*}{ NO } & \multicolumn{3}{|c|}{ Kondisi atau Logika } & \multirow{2}{*}{$\begin{array}{c}\text { Tampilan } \\
\text { LCD }\end{array}$} & \multirow{2}{*}{$\underset{\text { Kanopi }}{\text { Atap }}$} \\
\hline & Sensor Hujan & Sensor LDR & Sensor Suhu & & \\
\hline 1 & 0 & 1 & 1 & Hujan, Terang, $>29 \mathrm{C}$ & Tutup \\
\hline 2 & 0 & 0 & 1 & Hujan, Gelap, >29C & Tutup \\
\hline 3 & 0 & 1 & 0 & Hujan, Terang, $<29 \mathrm{C}$ & Tutup \\
\hline 4 & 0 & 0 & 0 & Hujan, Gelap, <29C & Tutup \\
\hline 5 & 1 & 1 & 1 & No Rain, Terang, $>29 C$ & Buka \\
\hline 6 & 1 & 0 & 1 & No Rain, Gelap, >29C & Buka \\
\hline 7 & 1 & 1 & 0 & No Rain, Terang, <29C & Buka \\
\hline 8 & 1 & 0 & 0 & No Rain, Gelap, <29C & Tutup \\
\hline
\end{tabular}

\section{KESIMPULAN}

Adapun simpulan dari penelitian ini adalah sebagai berikut:

1. Atap kanopi akan terbuka pada saat memenuhi 3 kondisi sebagai berikut:

a. Tidak hujan, cahaya terang, dan suhu lebih dari $29^{\circ} \mathrm{C}$

b. Tidak hujan, cahaya gelap, dan suhu lebih dari $29^{\circ} \mathrm{C}$

c. Tidak hujan, cahaya terang, dan suhu kurang dari $29^{\circ} \mathrm{C}$

2. Atap kanopi akan tertutup pada saat memenuhi 5 kondisi sebagai berikut:

a. Hujan, cahaya terang, dan suhu lebih dari $29^{\circ} \mathrm{C}$

b. Hujan, cahaya gelap, dan suhu lebih dari $29^{\circ} \mathrm{C}$

c. Hujan, cahaya terang, dan suhu kurang dari $29^{\circ} \mathrm{C}$

d. Hujan, cahaya gelap, dan suhu kurang dari $29^{\circ} \mathrm{C}$

e. Tidak hujan, cahaya gelap, dan suhu kurang dari $29^{\circ} \mathrm{C}$

3. Prototipe penggerak atap kanopi dapat bekerja sesuai dengan kondisi/logika yang diprogramkan pada perangkat lunak sistem mikrokontroler ATMega16.

6. DAFTAR PUSTAKA

[1] S. Sudarmadji, "ANALISA SISI POSITIF DAN NEGATIF PEMILIHAN BENTUK ATAP BERPENUTUP GENTENG UNTUK RUMAH TINGGAL," PILAR, vol. 10 , no. 1 , 2014.

[2] W. Budiharto and G. Rizal, "Belajar Sendiri 12 Proyek Mikrokontroler untuk Pemula," Elex Media Komputindo Jkt., 2007.

[3] W. Lingga, "Belajar Sendiri Mikrokontroller seri AVR, Simulasi dan Hardware," Yogyak. Andi, 2006.

[4] I. Jaelani, S. R. Sompie, and D. J. Mamahit, "Rancang Bangun Rumah Pintar Otomatis Berbasis Sensor Suhu, Sensor Cahaya, Dan Sensor Hujan," J. Tek.
Elektro Dan Komput., vol. 5, no. 1, pp. 110, 2015.

[5] A. Pudiatmoko, "Sistem Keamanan Kamar Kos Dengan Peringatan Alarm Dan SMS Berbasis Mikrokontroler ATMEGA32," PhD Thesis, Universitas Muhammadiyah Surakarta, 2013. 